M Dyson ${ }^{1}$, K Liddell $^{2}$, CJE Watson ${ }^{3}$, JA Bradley ${ }^{3}$ \& K Saeb-Parsy ${ }^{3}$

1 Faculty of Law, University of Oxford; 2 Faculty of Law, Centre for Law, Medicine and Life Sciences, University of Cambridge; 3 Department of Surgery and NIHR Cambridge Biomedical Research Centre, University of Cambridge

\section{Introduction}

A shortage of suitable organs has necessitated increased use of organs from deceased donors that are less than ideal. 'Less than ideal' or 'suboptimal' organs include those with poor anticipated outcomes or increased risks of disease transmission from elderly donors and from donors with histories of infections, cancer, smoking, and illicit drug use.

Assessment of the risks and benefits of transplantation are therefore difficult for both the patient and the clinicians, particularly since in the emergency setting in which these decisions often take place, many of the risks are either unknown or not accurately quantifiable.

The legal implications of transplantation of suboptimal organs should be examined alongside the medical, ethical and moral considerations ${ }^{1}$.

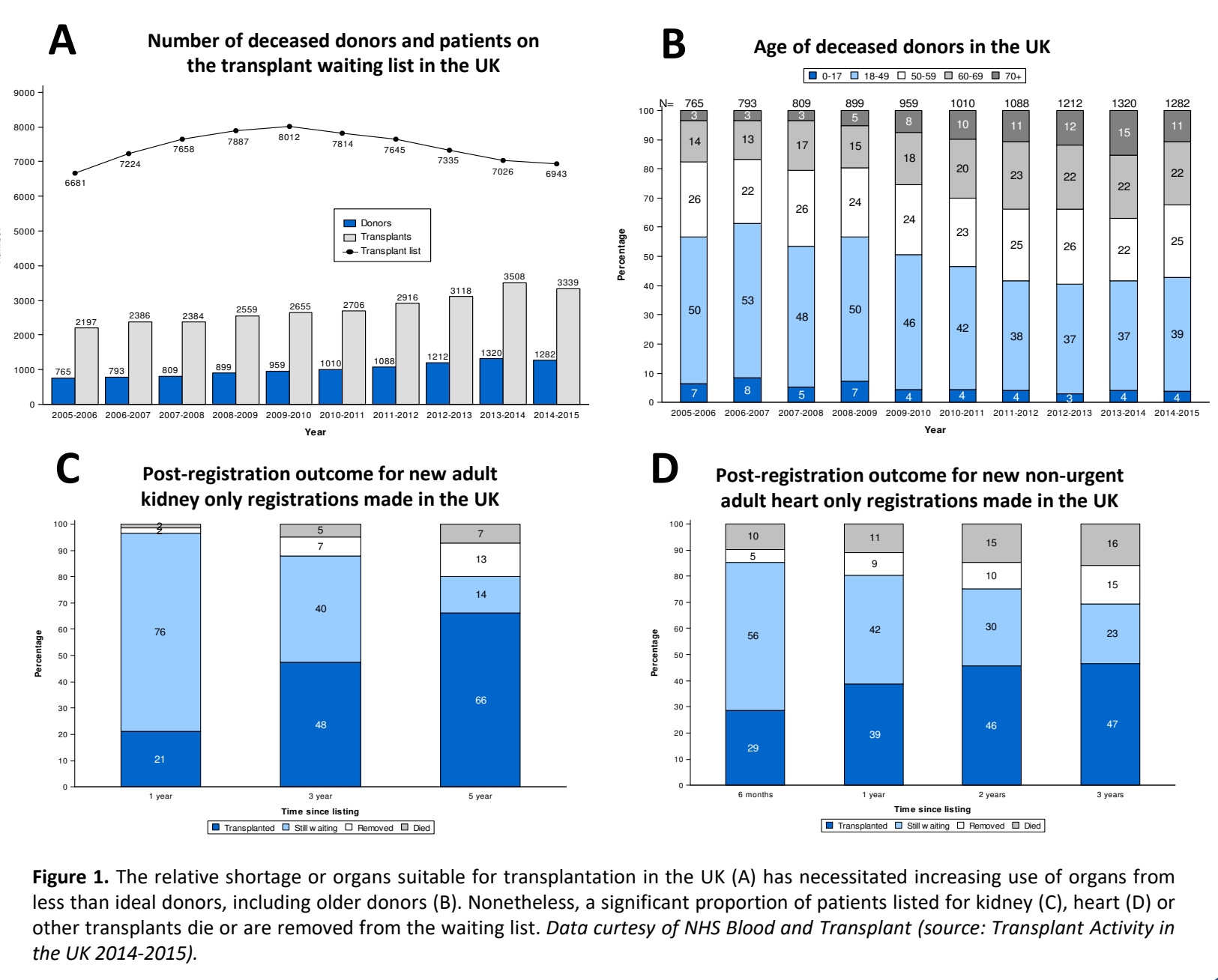

\section{Aims}

This paper aims to consider the legal regulation of transplantation of 'suboptimal' organs and to identify areas that require further research and attention.

\section{Relevant Legal Frameworks}

Civil liability, particularly tort law, has a vital role in regulating organ transplantation. There are 4 relevant torts:

Negligence; Product liability; Trespass to the person; Breach of statutory duty Only negligence and product liability play a significant role in this framework and are considered further.

\section{Negligence}

A duty of care an essential requirement in founding liability for negligence. Liability also requires fault on the part of the doctor. This occurs when the doctor's conduct fell short of the standards followed by a reasonable body of medical opinion, as exemplified by Bolam $v$ Friern Hospital Management Committee in $1957^{2}$.

The duty of care also requires the doctor to obtain the patient's informed consent. Following a UK Supreme Court judgement in Montgomery $v$ Lanarkshire Health Board ${ }^{3}$ in March 2015, the 'doctorfocused' Bolam test has now been replaced in the UK by a more 'patient-focused' duty to "...take reasonable care to ensure that the patient is aware of any material risks involved...". For transplant operations, the first practical result of Montgomery is that doctors are now formally under a specific duty to warn of all material risks in the operation, and discuss alternatives.

After establishing a breach of the duty of care, it must be proven that the doctor's breach caused legally recognised harm. Causation can be difficult to establish in medical cases and is complicated in transplantation by risks of staying on the waiting list.

\title{
Product Liability
}

The European Directive 85/374/EEC requires member states to have a system of strict liability (liability without fault) for all defective products. The policy decision to impose strict liability reflects a judgment about which risks individual consumers should bear, and which risk producers (usually profit-making entities) should bear.

\section{Is an organ a product?}

The Directive defines a "product" as "...any goods or electricity and... includes a product which is comprised in another product, whether by virtue of being a component part or raw material or otherwise". Normally "products" will be "property". In the landmark criminal law case of $R \vee K_{e} l l y^{4}$, body parts taken from the Royal College of Surgeons were considered property. The leading case in England on the Consumer Protection Act is $A v$ National Blood Authority ${ }^{5}$, where the Authority was liable for the harm suffered when patients received contaminated blood through transfusions. It is also thought to be the first English case where a claim under the Consumer Protection Act was successful in respect of a medical 'product'.

\section{Who is the producer?}

The Consumer Protection Act 1987 defines the producer as the person who won or abstracted it, or the person who gave it its essential characteristics through an industrial or other process. A 'producer' is therefore likely to include those involved in the retrieval, assessment, preparation and transplantation of an organ.

\section{When is a product defective?}

The Directive states that a product is defective if it "does not provide the safety which a person is entitled to expect". In the context of transplantation, it is not clear what a person is generally entitled to expect. The leading case is $A v$ National Blood: the public at large was entitled to expect that the blood would be free from infection. According to this judgement, the court will make an assessment of what consumers - in the context of transplantation, patients - are entitled to expect, not assess what patients actually expect. An appropriate view is that patients should be entitled to expect that an organ for transplant will have a degree of viability that accords with the risks of the organ transplant operation.

\section{What are the defences against a defective product?}

There are no provisions under the Directive for the defendant to argue that the victim's consent prevents liability under the Directive. The defendant is also expressly precluded from excluding liability. One defence which may apply to transplantation is the 'development risks' defence, where "the state of scientific and technical knowledge when [the defendant] put the product into circulation was not such as to enable the existence of the defect to be discovered". However, as exemplified in $A v$ National Blood, this defence is unlikely to assist unless the defect was entirely unknown and unpredictable at the time.

\section{Conclusions}

Understanding the way in which tort law regulates negative outcomes could strengthen aspects of the medical response to suboptimal organs. While consent is irrelevant to product liability, that does not mean that the process of "consenting" a patient might not in fact offer benefits against product liability. The same processes which are designed to obtain informed consent (and thus satisfy the duty under Montgomery) - including warning the patient about the risks, known and unknown, associated with the organ - are some of the most effective steps that producers of an organ can do to influence what is reasonable to expect from the organ.

Understanding organs as products could focus attention on the safety of the organ, not just the medical team's conduct. For example, instead of focussing on whether clinicians are at fault, the focus might be on improving and explaining reasonable expectations of safety, including giving more attention to ensuring the most appropriate organs reach the most suitable recipients, and expediting implantation of organs. 